\title{
Regional Variation in Attitude of Mental Health Professionals towards Tackling Illicit Drug-use and Drug-related Disorders
}

\author{
Olubusayo Akinola ${ }^{1}$, Wen-Hung Kuo ${ }^{2}$, John Oswald ${ }^{3}$, Olawunmi Obisesan ${ }^{4}$ \\ 1,2,3,4 Department of Public Health Science, Walden University \\ ${ }^{1}$ Economic Community of West African States (ECOWAS), Abuja, Nigeria \\ ${ }^{4}$ Emory University, Rollins School of Public Health, Atlanta, GA, USA
}

\begin{tabular}{l} 
Article Info \\
\hline Article history: \\
Received Mar 8, 2017 \\
Revised May 4, 2017 \\
Accepted May 19, 2017 \\
\hline
\end{tabular}

\section{Keywords:}

Attitude

Illicit drug use

Kruskal-wallis analysis mental health professionals regional variation

\begin{abstract}
This study sought to assess the attitudes of Mental Health Professionals (MHPs) towards tackling illicit drug use and drug-related disorders in Nigeria and to explore regional variations in attitude. Based on the validated Substance Abuse Attitude Survey (SAAS), a quantitative cross-sectional survey was conducted in a randomized sample of 292 MHPs practicing in neuropsychiatric hospitals and mental health departments of teaching hospitals from four geopolitical zones of Nigeria. A response rate of $81.1 \%$ was achieved. MHPs tended towards non-permissive, moralistic and stereotypic spectrum and exhibited distinctly defined attitude towards their professional role. The Kruskal-Wallis analysis established significant regional variation in the attitude of multidisciplinary MHPs, $H(3)=18.727$, $p<.0001$ reflecting a stochastic domination across the region; therefore a step-down follow-up analysis was conducted. This analysis revealed that the distribution of attitude total-score varies significantly between the Southsouth and the Southwestern region $(p<0.0001)$, the northeastern and southwestern region of the country $(p<0.028)$. A holistic approach towards standardization of drug treatment and care that takes into consideration possible regional variation in attitudes of MHPs should be implemented to foster the reintegration and rehabilitation of drug-using populations into the mainstream society.
\end{abstract}

Copyright () 2017 Institute of Advanced Engineering and Science. All rights reserved.

\section{Corresponding Author:}

Olubusayo Akinola,

Department of Public Health Science,

Walden University,

$100 \mathrm{~S}$ Washington Ave \#900, Minneapolis, USA.

Email: olubusayo.akinola@waldenu.edu

\section{INTRODUCTION}

Mental health professionals (MHPs) play a pivotal role in enhancing treatment outcomes and minimizing the adverse consequences of illicit drug use posed by drug-using populations to the general public [1,2]. The frequent contact by MHPs offers an increased opportunity for them to engage fully in the healthcare of patients dealing with drug-related problems [2,3]. However, caring for these individuals by MHPs has been documented in the literature as problematic. Research has identified that MHPs often exhibit attitudes that are deeply held and sometimes attributable to their life history, culture, values, and beliefs [1, 2], [4-6]. It is worth noting that the rehabilitation of people who use drugs (PWUDs) and their reintegration into the mainstream society is dependent on the positive and accepting attitudes of MHPs [7].

Although the treatment and recognition of mental disabilities in Nigeria predates written records, not until the early $20^{\text {th }}$ century was the mental health service delivery tailored according to western models [8]. The bulk of mental health services in the country is provided by departments of psychiatry, a number of general hospitals and eight regional federal neuropsychiatric hospitals [8]. Accessibility and availability of 
mental health services reflect rural to urban and northern to southern skew as most mental health services are in the southern and urban centers of the country [8]. Several studies conducted in Nigeria focused primarily on substance use in Nigerian colleges [9-14] amongst adolescents [15], use of psychoactive substances among Nigerian inmates [16], and trends in the use and abuse of substances [17]. This much cannot be said about studies on mental health professionals' attitude towards the care of patients dealing with drug-related problems in Nigeria.

In order to establish an up-to-date data on treatment capacity as it relates to PWUDs within Nigeria, the researchers, Onifade et al. [18], conducted a cross-sectional descriptive survey of the characteristics, spread, and types of available Substance Abuse Treatment (SAT) centers within the country. The thirty-one (31) SAT units that responded to the survey participated in training sessions at TREATNET centers and were located in the Northeastern and Southwestern geopolitical zones of the country. Sixteen of the SATs $(51.56 \%)$ were specialized residential units, 5(16.1\%) SATs were located in a prison and $17(54.8 \%)$ SATs were specialized non-residential units [18]. Findings from the descriptive study indicate lack of funds from health insurance, as funding were received from international organizations, private income of clients, and charitable donations [18]. Onifade et al. [18] established a great gap in meeting the needs of individuals that presents with substance use disorders due to a lack of comprehensive treatments. The researchers recommended the incorporation of drug treatment evaluation into treatment policies and systems so as to plan evidenced and need-based interventions. In addition, to further establish the efficiency and effectiveness of interventions that are consistent with drug dependence treatment and care services [18].

Ekpenyong [13] assessed the perception, extent, and causes of drug use amongst Nigerian students. In addition to the study objectives, the researcher evaluated and analyzed the strategies employed to tackle illicit drug use and substance abuse generally, the shortcomings and effectiveness of the strategies in place to address this menace in the Nigerian secondary schools [13]. The study of Ekpeyong [13], guided theoretically by the modified social stress model [19], provided an in-depth understanding of the protective and risk factors that could predispose an individual to drug use and substance abuse. Pupils of four public secondary schools in the local government area of Southern Ijaw, Community secondary school Angiana, Government secondary school, Amassoma, Community secondary school, Eniwari and the Southern Ijaw secondary school Oporoma, all in Bayelsa state Nigeria, were purposively sampled.

Findings from the study revealed that over half of the study participants $(60 \%, 222)$ had negative perception towards substance abuse and drug use generally; approximately $31 \%$ (116) of the respondents had positive perception while $8.6 \%$ of the respondents reflected indifferent perception towards the use and abuse of substances [13]. With a rate of $33.8 \%$ drug use amongst the secondary school students that were surveyed, the researchers documented the types of substances abused, and these includes bhang, marijuana and alcohol [13]. The effect of substance abuse on cognition and behavior of students documented by the researchers includes withdrawal, lack of concentration, indiscipline, lack of interest in schoolwork and poor relationship with others [13]. The researchers recommended educational intervention programs, punitive measures and behavioral modification techniques as ways of mitigating the threat and challenges of substance abuse amongst Nigerian secondary school students [13].

James and Omoregba [20] assessed the opinions and attitudes of Nigerian medical students towards individuals that use and abuse substances. Study participants were medical students of the Federal neuropsychiatric hospital, who had completed their ten-week psychiatry clerkship and are in their fifth year [20]. A response rate of $95.24 \%$ (210 students) was obtained and the respondents were provided a modified version of the substance abuse attitude survey (SAAS) [20]. Findings from the study reflected positive attitudes towards individuals that abuse and use psychoactive substances with an overall mean score of 86.18 (12.29). Female medical students had lower mean score (85.18) compared with their male colleagues (87.17) while respondents with family history of cannabis use $(p<0.001)$, nicotine $(p<0.002)$, tobacco $(p<0.001)$ and alcohol use $(p<0.02)$ showed less stigmatizing attitudes towards clients that use and abuse psychoactive substances [20]. The researchers suggested incorporating training on psychoactive substances in continuous professional developments beyond residency years and medical schools [20].

The researchers, Jack-ide et al. [21] explored the direct impact of the Nigerian mental health policy formulated in 1991 on the provision of mental health services at a federal neuropsychiatric hospital in Nigeria. To identify challenges, difficulties, and implications of mental health policy of delivering services, nurses working at the neuropsychiatric hospital, Rivers state, Nigeria were purposively recruited in the study [21]. Twenty nurses participated in a semi-structured in-depth interview, and information about their experiences in providing services was evaluated within the context of the policy [21]. Four domains for systematic evaluation, outcomes, resources, content and provision were identified as elements for mental health program implementation and service assessments [21]. Findings from the study reflected negative and stigmatizing attitudes amongst mental health nurses, policy failure, and lack of provision for the post of a director in the Nigerian Ministry of Health as a major obstacle to proper governance and high priority status 
[21]. Inference deduced from the study suggests the need for the implementation of mental health treatment policies to reduce associated burdens, improve uptake and access to treatment [21].

Several studies have examined associations between attitude and MHPs' professional role identity. However, there's a notable absence of empirical studies that have examined regional variation in attitudes of MHPs. Given that the attitudes of healthcare workers play a major role in treatment retention and affect the quality management of illicit drug-related disorders [22, 23], It was, therefore, particularly important to understand possible regional variations in attitude of MHPs that could relatively explain the variance in treatment completion and retention of PWUDs.

\section{MATERIALS AND METHODS}

A quantitative cross-sectional survey was conducted in a randomized sample of 292 MHPs practicing in neuropsychiatric hospitals and mental health departments of teaching hospitals from 4 geopolitical zones of Nigeria. The group of MHPs surveyed included psychiatrists, addiction counselors, psychologists, psychiatric nurse, peer counselors, and social workers. Study participants were drawn from four geopolitical zones of the country (southwest and south-southern zones, northwest, and northeastern zones of the country). The states surveyed from each zone were selected through simple random sampling to have an unbiased representation of MHPs in the country. Hospitals selected per zone were federal neuropsychiatric hospitals, teaching hospitals, and state neuropsychiatric hospitals. The required sample size was computed a priori using ANOVA fixed effects, special main effects, and interactions.

\subsection{Compliance with ethical standards}

Ethics approval for this study was obtained from Walden University Institutional Review Board and the National Health Research Ethics Committee of Nigeria (NHREC). In addition, informed consents were obtained from MHPs who responded to the survey.

\subsection{Instrumentation and operationalization of constructs}

The instrument adapted in this study is the substance abuse attitude survey (SAAS) and permission to adapt the validated version of the questionnaire was granted by the copyright holder. In addition to this instrument, the demographic information of the participants served as the independent constructs of the study.

To allow for modification of wordings, for possible detection of ambiguity, and to identify wordings that might be too sensitive for the Nigerian culture, preliminary testing of the SAAS was conducted with 10 MHPs practicing in one of the zones that were excluded from the study (north central zone of the country). For the non-moralism subscale, the statement clergymen should not drink in public [24] was considered unidirectional and was removed from the questionnaire because the expected role and conduct of clergymen in the Nigerian society was to abstain both privately and publicly from illicit drug use. Because heroin and cannabis are considered illegal under the Nigerian law and attract the same punishment for trafficking and use, the statement classified under the subscale of non-moralism, the laws governing the use of heroin should be the same [24], was removed from the questionnaire. The statements tobacco smoking should be allowed in high school and cannabis use can be healthy experimentation under the subscale of permissiveness [24] were also removed from the questionnaire because they were considered too sensitive in the Nigerian culture.

For the subscale of non-stereotypes, the statement chronic substance dependent people who refuse treatment should be legally committed to long-term care [24], was removed from the questionnaire because of the absence of any law that legally commits an individual to any form of substance dependent treatment in the country. The preliminary testing of the questionnaire also revealed that the term hippie style clothing was not a commonly used term in the country [20]. Therefore, the statement people who dress in hippy style clothing probably use psychedelic drug under the subscale of non-stereotype was removed from the questionnaire [20]. Because this study was focused primarily on illicit drug use and not alcohol, questions from the SAAS were modified with permission from the copyright holders to reflect attitudes toward illicit drug use. Items, which reflected both "alcoholism or drug addiction", were made to read "drug addiction", which included factor 2, treatment intervention subscale (items 8, 9, 10,13) and factor 4, treatment optimism subscale (items 23, 24, 25). Items from factor 1, permissiveness subscale that reflects only "use of alcohol" were made to read "drug use" (items 5 \& 7). The SAAS was modified to a 31-item as a composite scale and was adopted for this study as shown in Table 1. 
Table 1. Subgroup of Attitudes Identified by the SAAS

\begin{tabular}{|c|c|}
\hline Permissiveness & $\begin{array}{l}\text { Individual acceptance that illicit drug use is a continuum of typical human behavior. The } \\
\text { subgroup consists of } 7 \text { questions (Q1-Q7). }\end{array}$ \\
\hline $\begin{array}{l}\text { Treatment } \\
\text { Intervention }\end{array}$ & $\begin{array}{l}\text { Implies the consistent and precise conceptualization of the extent to which drug-related } \\
\text { treatment is received, delivered, and used as intended. The subgroup consists of } 6 \\
\text { questions (Q8 - Q13) }\end{array}$ \\
\hline Non-stereotypes & $\begin{array}{l}\text { Describes the extent to which MHPs display lack of fixed or over generalized belief } \\
\text { toward individuals that use illicit drugs. The subgroup consists of } 8 \text { questions (Q14 - Q21) }\end{array}$ \\
\hline Treatment Optimism & $\begin{array}{l}\text { Participants' display of positivity toward the successful outcome of drug dependence care } \\
\text { and treatment. The subgroup consists of } 4 \text { questions (Q22 - Q25) }\end{array}$ \\
\hline Non-moralism & $\begin{array}{l}\text { Displays the degree to which the respondents are not being judgmental about a particular } \\
\text { principle of conduct or system of values that defines the extent to which illicit drug use is } \\
\text { deemed wrong or right. The subgroup consists of } 6 \text { questions (Q26-Q31). }\end{array}$ \\
\hline
\end{tabular}

\subsection{Statistical analysis}

Descriptive statistics, consisting of numerical and graphical techniques for data summarization, were performed and used to analyze the frequency of data distributions on numerical and categorical variables (socio-demographic variables). The Kruskal-Wallis test was used to assess the hypothetical variation in MHPs' attitude from different regions of the country. It is noteworthy that the non-parametric analysis of MHPs' attitude total score (dependent variable) was conducted due to a violation of the assumption of Shapiro-Wilks test for normality $(p<0.0001)$. In addition, the histogram of attitude total score for region reflected negatively skewed graphs that are platykurtic (Figure 1). Northwestern (NW) region had a skewness of $-0.427(S . E=0.254)$ and a Kurtosis of $-0.136(S . E=0.503)$, Northeastern (NE) region had a skewness of -0.229 (S.E=0.311) and a kurtosis of 0.333 (S.E=0.613), South-southern (SS) region had a skewness of $-0.965(\mathrm{~S} . \mathrm{E}=0.267)$ and a kurtosis of $0.547(\mathrm{~S} . \mathrm{E}=0.529)$ while the Southwestern $(\mathrm{SW})$ region had a skewness of -0.536 (S.E=0.319) and a kurtosis of 0.237 (S.E=0.628) (Figure 1).

Therefore, a rank-based Kruskal-Wallis non-parametric test was conducted to determine if MHPs' attitude total score from four different geopolitical zones (NE, NW, SS and SE zones of Nigeria) would be significantly different. The Kruskal-Wallis test was conducted based on the assumptions that the dependent variable (attitude total score) is measured at an ordinal level and the independent variable (region) consists of four categorical levels, with an independence of observation as shown in Table 2.

Table 2. Test of Normality for Attitude Total Score and Region

\begin{tabular}{ccc}
\hline & \multicolumn{2}{c}{ Shapiro-Wilk } \\
Variable (Region) & $d f$ & Statistics \\
\hline NW & 90 & $0.911^{* * *}$ \\
NE & 59 & $0.879 * * *$ \\
SS & 81 & $0.859 * * *$ \\
SW & 56 & $0.887 * * *$ \\
\hline
\end{tabular}

Note. $\mathrm{NW}=$ northwestern region, $\mathrm{NE}=$ northeastern region, $\mathrm{SS}=$ southwestern region,

$\mathrm{df}=$ degree of freedom, $* * * \mathrm{p}<0.0001$. (The distribution of the data set was computed a-priori to establish the likelihood to have a normal distribution for the variables, attitude total score and region)

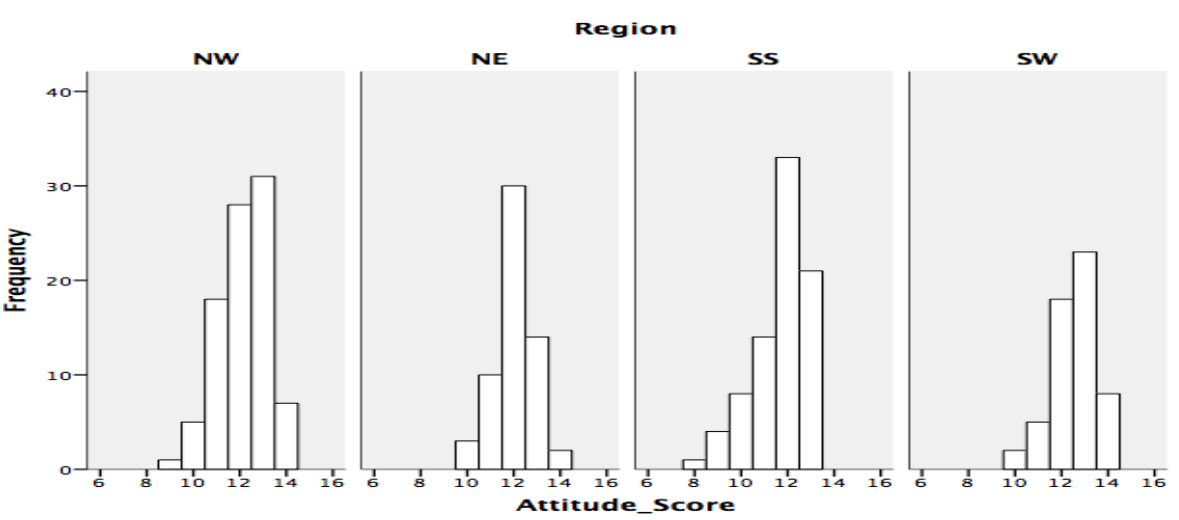

Figure1. Histogram of Attitude Total Score for Different Geopolitical Zones of Nigeria 
Graphical representation for the distribution of attitude total score for four geopolitical zones of Nigeria reflects atypical distribution:

SS region: skewness of $-0.965(\mathrm{~S} . \mathrm{E}=0.267)$ and a kurtosis of $0.547(\mathrm{~S} . \mathrm{E}=0.529)$,

SW region: skewness of $-0.536(\mathrm{~S} . \mathrm{E}=0.319)$ and a kurtosis of $0.237(\mathrm{~S} . \mathrm{E}=0.628)$,

NE region: skewness of $-0.229(\mathrm{~S} . \mathrm{E}=0.311)$ and a kurtosis of $0.333(\mathrm{~S} . \mathrm{E}=0.613)$,

NW region: skewness of $-0.427(\mathrm{~S} . \mathrm{E}=0.254)$ and a Kurtosis of $-0.136(\mathrm{~S} . \mathrm{E}=0.503)$.

\subsection{Kruskal-Wallis analysis}

This part of the study outlines the main features of the Kruskal- Wallis analysis. For the purpose of this study, a rank-based non-parametric test was used to determine if there are statistically significant differences in region (independent variable of four groups) and attitude of MHPs.

$$
H=\frac{12}{n(n+1)} \sum_{i=1}^{k} \frac{R_{i}^{2}}{n_{i}}-3(n+1)
$$

In this equation, $n=$ total sample size of MHPs (where $n=286$ valid responses from the 292 survey from the MHPs. Five surveys were removed because they were outliers. Another survey was removed when, after conducting residual diagnostics to validate the model fit, it was taken to be a univariate outlier). $n_{i}$ is the sample size of each of the region surveyed $(\mathrm{NE}=31.5 \%, \mathrm{NW}=20.6 \%, \mathrm{SS}=28.3 \%$, and $\mathrm{SW}=19.6 \%)$ and $R_{i}$ is the sum ranks for each groups.

\section{RESULTS AND ANALYSIS}

Two hundred and ninety two (292) MHPs responded to the survey and a response rate of $81.1 \%$ was achieved. However, when evaluating the responses for outliers and missing cases and to ensure the surveys were completed accurately, five surveys were removed. Another survey was removed when, after conducting residual diagnostics to validate the model fit, it was taken to be a univariate outlier (extreme case). Thus, the responses from 286 participants were used for final data analysis.

\subsection{Baseline demographic characteristics of the study population}

Just over half $(51.7 \%[n=148])$ of the MHPs who responded to the survey were male. The majority (63.3\% [ $n=181])$ was aged between 21 and 40 years. More than $80 \%(n=235)$ of the respondents had undergraduate degree, and $13.3 \%(\mathrm{n}=38)$ and $4.5 \%(\mathrm{n}=13)$ had obtained either a master's degree or $\mathrm{PhD}$ at the time of the survey. Majority of the participants $(70.6 \%[n=202])$ had practiced for less than 16 years. Just over half 58\% $(n=166)$ of the 286 MHPs included for final data analysis were psychiatric nurses, $7 \%(n=20)$ were psychologists, $18.9 \%(n=54)$ were social workers, $2.1 \%(n=6)$ were addiction counselors, $1.4 \%(n=4)$ were peer counselors, and $12.6 \%(n=36)$ were psychiatrists. Of the useable questionnaire, $31.5 \%(n=90)$ were obtained from the northwestern region, $20.6 \%(n=59)$ were filled by MHPs from the northeastern region. Approximately $28 \%(\mathrm{n}=81)$ and $19.6 \%(\mathrm{n}=56)$ were from the south-south and southwestern region of the country respectively. Frequency of distribution and demographics percentages are presented in Table 3.

The first research question assessed the extent to which Nigerian MHPs' exhibit positive versus negative attitude regarding their professional role identity in tackling illicit drug use in Nigeria. Attitudes of multidisciplinary MHPs were assessed using the substance abuse attitude survey (SAAS) developed by Chappel et al. [24]. The validated SAAS adopted in this study consists of 31 questions and responses were based on a four-point Likert scale to avoid neutral responses. All questions were associated with fiveattitudinal subscale factors and these include: 1) permissiveness, 2) treatment intervention, 3) nonstereotypes, 4) treatment optimism and 5) non-moralism (Table 1).

MHPs who responded to the survey tended toward the non-permissive and stereotypic spectrum. Almost all the study participants, 93.7\% $(\mathrm{n}=268, M=1.94, S D=0.243)$ disagreed that marijuana should be legalized and, $89.2 \%(\mathrm{n}=255, M=1.89, S D=0.311)$ believed that the personal use of drugs should not be legal even in the confines of the homes of individuals use illicit drugs (Table 4). A substantial number of the participants, $86 \%(\mathrm{n}=246, M=1.14, S D=0.347)$ expressed the opinion that people who smoke will indulge in marijuana use, and that it is almost impossible for addicts to recover because heroin is addicting. Although the participants were quite moralistic, majority, $73.1 \%(\mathrm{n}=209, M=1.73, S D=0.444)$ were against angry confrontation when treating drug-using clients. Responses on treatment intervention and treatment optimism were fairly homogenous as MHPs displayed positivity toward successful outcome of drug dependence treatment and care as shown in Table 4. 
Table 3. Frequencies of Distribution for Respondents' Demographics by Profession

\begin{tabular}{|c|c|c|c|c|c|c|c|}
\hline Variables & $\begin{array}{c}\text { Psychiatrist } \\
\%(n=36)\end{array}$ & $\begin{array}{c}\text { Nurse } \\
\%(\mathrm{n}=166) \\
\end{array}$ & $\begin{array}{c}\text { Addiction Counselor } \\
\%(\mathrm{n}=6)\end{array}$ & $\begin{array}{c}\text { Social Worker } \\
\%(\mathrm{n}=54)\end{array}$ & $\begin{array}{l}\text { Psychologist } \\
\%(n=20)\end{array}$ & $\begin{array}{c}\text { Peercounselor } \\
\%(n=4)\end{array}$ & $\begin{array}{c}\text { Total } \\
\%(\mathrm{n}=286)\end{array}$ \\
\hline \multicolumn{8}{|l|}{ Region } \\
\hline Northeast (NE) & 19.4 & 38.6 & 0.0 & 20.4 & 10.0 & 25.0 & 31.5 \\
\hline Northwest (NW) & 47.2 & 17.5 & 33.3 & 9.3 & 30.0 & 0.0 & 20.6 \\
\hline South-South (SS) & 19.4 & 27.7 & 16.7 & 31.5 & 45.0 & 25.0 & 28.3 \\
\hline Southwest (SW) & 13.9 & 16.3 & 50.0 & 20.4 & 15.0 & 50.0 & 19.6 \\
\hline \multicolumn{8}{|l|}{ Age group } \\
\hline $21-25$ & 0.0 & 15.7 & 0.0 & 5.6 & 5.0 & 0.0 & 10.5 \\
\hline $26-30$ & 30.6 & 19.3 & 33.3 & 20.4 & 25.0 & 25.0 & 21.7 \\
\hline $31-35$ & 16.7 & 12.7 & 16.7 & 25.9 & 35.0 & 50.0 & 17.8 \\
\hline $36-40$ & 22.2 & 9.0 & 16.7 & 18.5 & 20.0 & 0.0 & 13.3 \\
\hline $41-45$ & 19.4 & 14.5 & 0.0 & 11.1 & 10.0 & 25.0 & 14.0 \\
\hline$>45$ & 11.1 & 28.9 & 33.3 & 18.5 & 5.0 & 0.0 & 22.7 \\
\hline \multicolumn{8}{|l|}{ Educ. Attainment } \\
\hline First Degree & 58.3 & 91.0 & 83.3 & 85.2 & 45.0 & 75.0 & 82.2 \\
\hline Masters & 11.1 & 8.4 & 16.7 & 13.0 & 55.0 & 25.0 & 13.3 \\
\hline Ph.D. & 30.6 & 0.6 & 0.0 & 1.9 & 0.0 & 0.0 & 4.5 \\
\hline \multicolumn{8}{|l|}{ Gender } \\
\hline Male & 22.2 & 58.4 & 50.0 & 40.7 & 30.0 & 50.0 & 48.3 \\
\hline Female & 77.8 & 41.6 & 50.0 & 59.3 & 70.0 & 50.0 & 51.7 \\
\hline \multicolumn{8}{|l|}{ Years of practice } \\
\hline$<5$ & 27.8 & 29.5 & 33.3 & 37.0 & 50.0 & 0.0 & 31.8 \\
\hline $5-10$ & 41.7 & 20.5 & 0.3 & 24.1 & 25.0 & 75.0 & 24.5 \\
\hline $11-15$ & 22.2 & 12.0 & 50.0 & 9.3 & 20.0 & 25.0 & 14.3 \\
\hline $16-20$ & 5.6 & 9.6 & 0.0 & 13.0 & 5.0 & 0.0 & 9.1 \\
\hline$>20$ & 2.8 & 28.3 & 16.7 & 16.7 & 0.0 & 0.0 & 20.3 \\
\hline
\end{tabular}

Table 4. Frequency of Responses for Attitude Subgroups of the SAAS

\begin{tabular}{|c|c|c|c|c|}
\hline Questions & $\begin{array}{l}\text { Strongly } \\
\text { Agree }\end{array}$ & Agree & $\begin{array}{l}\text { Strongly } \\
\text { Disagree }\end{array}$ & Disagree \\
\hline \multicolumn{5}{|l|}{ Factor 1: Permissiveness } \\
\hline 1. Marijuana should be legalized & 8 & 10 & 199 & 69 \\
\hline 2. Personal use of drugs should be legal in the confines of one's home & 13 & 18 & 130 & 125 \\
\hline 3. Daily use of one marijuana cigarette is not necessarily harmful & 9 & 17 & 62 & 198 \\
\hline 4. It can be normal for a teenager to experiment with drugs & 47 & 15 & 149 & 75 \\
\hline $\begin{array}{l}\text { 5. Lifelong abstinence is a necessary goal in the treatment of problematic } \\
\text { drug use }\end{array}$ & 113 & 126 & 17 & 30 \\
\hline $\begin{array}{l}\text { 6.Once a person becomes drug-free through treatment, he can } \\
\text { never become a social user }\end{array}$ & 32 & 42 & 89 & 123 \\
\hline 7. Parents should teach their children how to use drugs & 11 & 90 & 153 & 32 \\
\hline \multicolumn{5}{|l|}{ Factor 2: Treatment Intervention } \\
\hline $\begin{array}{l}\text { 8. Family involvement is a very important part of the treatment of drug } \\
\text { addiction }\end{array}$ & 81 & 199 & 2 & 4 \\
\hline $\begin{array}{l}\text { 9. The best way to treat drug-dependent people is to refer them to a } \\
\text { good treatment program }\end{array}$ & 148 & 131 & 6 & 1 \\
\hline 10. Group therapy is very important in the treatment of drug addiction & 75 & 195 & 5 & 11 \\
\hline $\begin{array}{l}\text { 11. Urine drug screening can be an important part of treatment of } \\
\text { drug misuse }\end{array}$ & 186 & 58 & 3 & 39 \\
\hline $\begin{array}{l}\text { 12. Long-term outpatient treatment is necessary for the treatment of drug } \\
\text { addiction }\end{array}$ & 121 & 115 & 14 & 36 \\
\hline $\begin{array}{l}\text { 13. Paraprofessional counselors can provide effective treatment for } \\
\text { drug misusers }\end{array}$ & 95 & 122 & 49 & 20 \\
\hline \multicolumn{5}{|l|}{ Factor 3: Non-Stereotypes } \\
\hline 14. People who use marijuana usually do not respect authority & 198 & 36 & 4 & 48 \\
\hline 15. Smoking leads to marijuana use, which, in turn leads to hard drugs & 96 & 150 & 18 & 22 \\
\hline 16. Marijuana use leads to mental illness & 196 & 78 & 8 & 4 \\
\hline $\begin{array}{l}\text { 17. Heroin is so addicting that no one can really recover once he/she } \\
\text { becomes an addict }\end{array}$ & 39 & 102 & 72 & 73 \\
\hline 18. All heroin use leads to addiction & 150 & 77 & 16 & 43 \\
\hline 19. Weekend users of drugs will progress to drug misuse & 201 & 52 & 13 & 20 \\
\hline 20. A hospital is the best place to treat a drug addict & 131 & 68 & 16 & 71 \\
\hline 21. Recreational drug use precedes drug misuse & 157 & 92 & 3 & 34 \\
\hline \multicolumn{5}{|l|}{ Factor 4: Treatment Optimism } \\
\hline 22. Drug addiction is a treatable illness & 112 & 153 & 8 & 13 \\
\hline $\begin{array}{l}\text { 23. A drug-dependent person who has relapsed several times } \\
\text { probably cannot be treated }\end{array}$ & 62 & 26 & 97 & 101 \\
\hline 24. Most drug-dependent persons are unpleasant to work with & 199 & 97 & 23 & 57 \\
\hline $\begin{array}{l}\text { 25. A drug-dependent person cannot be helped until he/she has hit } \\
\text { "rock bottom" }\end{array}$ & 41 & 39 & 104 & 102 \\
\hline Factor 5: Non-moralism & & & & \\
\hline
\end{tabular}




\begin{tabular}{|c|c|c|c|c|}
\hline Questions & $\begin{array}{l}\text { Strongly } \\
\text { Agree }\end{array}$ & Agree & $\begin{array}{l}\text { Strongly } \\
\text { Disagree }\end{array}$ & Disagree \\
\hline 26. Street pushers are the initial source of drugs for young adult & 111 & 109 & 14 & 14 \\
\hline $\begin{array}{l}\text { 27. Drug misuse is so dangerous that it can destroy the youth of our } \\
\text { country if not controlled by law }\end{array}$ & 183 & 95 & 2 & 6 \\
\hline 28. Angry confrontation is necessary in the treatment of drug addicts & 27 & 50 & 10 & 199 \\
\hline 29. Drug misusers should only be treated by specialists in the field & 144 & 94 & 36 & 12 \\
\hline 30. Addiction to drug is associated with a weak will & 113 & 113 & 18 & 42 \\
\hline 31. Using any hard drug shortens one's life span & 108 & 159 & 7 & 12 \\
\hline
\end{tabular}

Research question 2: Is there a regional variation in attitude of multidisciplinary MHPs when handling drug-using populations in Nigeria. H0: There will be no significant regional variation in attitude amongst multidisciplinary MHPs when handling drug-using populations in Nigeria. The Kruskal-Wallis hypothesis test summary with a degree of freedom of three $(d f=3)$ and a $\rho$ value of less than 0.05 established significant regional variation in the attitude of multidisciplinary MHPs, $H(3)=18.727, \rho<0.0001$ (Table 5). Therefore, the null hypothesis was rejected.

Table 5. Kruskal Wallis Hypothesis Test Summary

\begin{tabular}{lcccc}
\hline \multicolumn{1}{c}{ Null Hypothesis } & $\mathrm{H}$ & $\mathrm{df}$ & $\mathrm{p}$ & Decision \\
\hline $\begin{array}{l}\text { The distribution of attitude score } \\
\text { is the same across categories of } \\
\text { region }\end{array}$ & 18.727 & 3 & .000 & $\begin{array}{c}\text { Reject the null } \\
\text { hypothesis }\end{array}$ \\
\hline
\end{tabular}

Note. $X^{2}=$ Chi-square, $d f=$ degree of freedom, $p=$ statistical significance at $95 \%$ C.I.

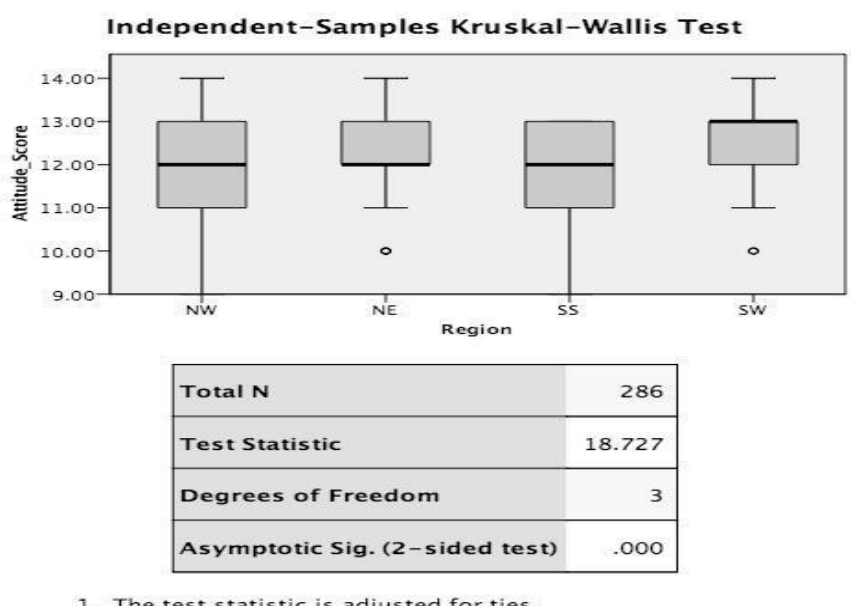

Figure 2. A rank-Based Kruskal-Wallis Non-Parametric Test of MHPs' Attitude Total Score

The rank-based kruskal-Wallis test revealed statistically significant difference in attitude score (attitude of MHPs) within the different geopolitical zones of Nigeria. The distribution of attitude score is therefore, not the same across categories of region

The significant Kruskal Wallis analysis $(p<0.0001)$ revealed that at least one of the four regions surveyed stochastically dominates another region; therefore a step-down follow up analysis based on the distribution of attitude total score was conducted. 


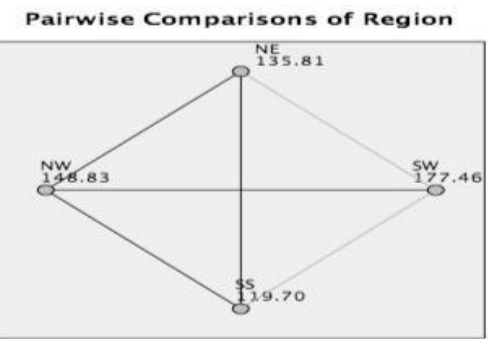

Each node shows the sample average rank of Region.

\begin{tabular}{|c|c|c|c|c|c|}
\hline Sample1-Samplez & $\begin{array}{l}\text { Test } \\
\text { Statistic }\end{array}$ & $\begin{array}{l}\text { Std. } \\
\text { Error }\end{array}$ & $\begin{array}{l}\text { Std. Test } \\
\text { Statistic }\end{array}$ & sig. & Adj.Sig. \\
\hline SS-NE & 16.101 & 13.501 & 1.193 & .233 & 1.000 \\
\hline SS-NW & 29.124 & 12.081 & 2.411 & .016 & .096 \\
\hline ss-sw & -57.761 & 13.708 & -4.214 & .000 & .000 \\
\hline NE-NW & 13.023 & 13.213 & .986 & .324 & 1.000 \\
\hline NE-SW & -41.659 & 14.716 & -2.831 & .005 & .028 \\
\hline$N W-S W$ & -28.637 & 13.425 & -2.133 & .033 & .198 \\
\hline
\end{tabular}

Figure 3. Kruskal-Wallis Step-Down Follow-up Analysis: Pairwise Comparisons of Region Based on the Distribution of Attitude Total Score

The results showed that the geopolitical region wherein the MHPs practice significantly affects their attitude towards the treatment of PWUDs. The step-down follow up analysis further revealed significant changes as you move from the SS and NE to the SW region of the country. Step-down follow-up analysis revealed that the distribution of attitude total score varies significantly between the South-south and the southwestern region $(p<0.0001)$. There was also a significant variation in attitude between MHPs living in the northeastern and southwestern region of the country $(p<0.028)$ (Figure 3$)$.

\section{DISCUSSION}

In this study, MHPs tended towards the non-permissive and stereotypic spectrum as almost all the study participants disagreed to legalizing marijuana and expressed the fact that it's abnormal for a teenager to experiment with drugs. The response from the study participants is in line with the studies conducted by Kelleher et al. [25] and Kalebka et al. [1] amongst healthcare practitioners in different emergency centers, as majority of the respondents in their study disagreed to legalization of marijuana. The MHPs that responded to the survey reiterated the importance of life-long abstinence and this is in line with the publications of the National Institute on Drug Abuse (NIDA), which advocates extended abstinence as a requirement for sustained drug recovery, due to increase in the odds of recovery from addiction after an extended period of abstinence [26].

Participants maintained a stereotypic principle of conduct as majority agreed that individuals who smoke would eventually use hard drugs while those that indulge in the use of marijuana would not respect authority. Numerous studies have established negative stereotypic attitudes towards individuals that misuse substance [27-29] and consequently reported lower regard and unwillingness to provide services to this population group. In addition to these opinions, almost all the respondents believe that marijuana use will lead to mental illness. This is in line with several studies that have established association of marijuana use with the risk of affective or psychotic mental health outcomes [30-32]. Research conducted by Galisky et al. [33] demonstrated the activation of stereotypic behavior and its strong effects on subtle overt behavior and hostile intent. Findings from their study established the importance of developing healthy bond to reduce prejudice and stereotyping. As described by Goldstein et al. [34], the ability to understand individuals' feelings, intentions, thoughts and motivations is embedded in perspective taking, which in turn can reduce the negativity of stereotypic attitude.

Majority of the respondents expressed the importance of controlling drug use by law because the use of drugs could totally ruin the lives of youths and pointed to the fact that street pushers expose young people to drug use. Although the respondents exhibited a high degree of moral conservatism and associated addiction to drugs as weak will, they disagreed to angry confrontation when treating individuals that misuse substances. This is in line with the brief intervention guidelines, motivating young adults towards substance abuse treatment and care as described by Miller et al. [35]. Research conducted by Vauclair et al. [36] established that moralistic attitudes displayed by individuals could be based on the discourse of a community 
or a particular group that appraise themselves as been right or wrong based on social obligations, roles and interpersonal duties. These researchers explored the influence of cultural values against the backdrop of moral attitudes and demonstrated that individual moral attitudes, as expressed by MHPs in this study, could be due to several cultural 'embeddedness' [36].

Although there's a notable absence of empirical studies that have explored regional variation in attitudes of MHPs towards service provision to drug using populations, this current study established statistical significant regional variation in the attitudes of multidisciplinary MHPs towards non-moralism, treatment optimism, non-stereotypes, permissiveness and treatment interventions as measured by the SAAS when handling dug-using populations in Nigeria. Step-down follow up analysis, revealed that the distribution of attitude total score vary significantly between the South-southern and southwestern region. There was also a significant variation in attitude between MHPs living in the southwestern and northeastern region of Nigeria.

It can be argued that variations in attitudes based on structural systems within which MHPs work as barriers to optimum care and treatment is probably not peculiar to Nigeria. Todd et al. [37] established regional variation in service structures and treatment approaches as a major barrier that affects optimal care delivery to clients that presents with mental health disorders and coexisting substance use in New Zealand. The researchers pointed out structural deficits and uncoordinated treatment and care for individuals with coexisting disorders as barriers to optimum care [37]. Chu et al. [38] reiterated the importance of regional factors such as geographical variation and differences in healthcare settings as essential to comprehensively and accurately describe healthcare professionals' attitudes towards substance abuse and related disorders.

\section{CONCLUSION}

This study emphasizes the impact of regional variations on attitude based on possible different structural systems and treatment approaches in service delivery. A holistic approach towards standardization of drug dependence treatment and care that takes into consideration cultural differences, diverse religious and ethnic mix predominating in the different geopolitical zones of the country should therefore be implemented in order to foster the reintegration and rehabilitation of this population group into the main stream society. Lastly, drug dependence treatment, related interventions and policies should be targeted at reducing stereotypic attitude and stigmatization of drug-using populations that will translate into improved overall mental and physical wellbeing of individuals that presents with drug-related disorders.

\section{REFERENCES}

[1] R. R. Kalebka, et al., "A survey of attitudes towards patient substance abuse and addiction in the emergency centre," African Journal of Emergency Medicine, vol/issue: 3(1), pp. 10-17, 2013.

[2] J. D. Livingston, et al., "The effectiveness of interventions for reducing stigma related to substance use disorders: A systematic review," Addiction, vol. 107, pp. 39-50, 2012.

[3] C. E. Grella, et al., "Perceptions of need and help received for substance dependence in a national probability survey," Psychiatric Services, vol. 60, pp. 1068-1074, 2009.

[4] G. Gilchrist, et al., "Staff regard towards working with substance users: A European Multi-centre study," Addiction, vol. 106, pp. 1114-1125, 2011.

[5] L. McFarling, et al., "Stigma as a barrier to substance abuse and mental health treatment," Military Psychology, vol/issue: 23(1), pp. 1-5, 2011.

[6] L. C. V. Boekel, et al., "Healthcare professionals' regard towards working with patients with substance use disorders: Comparison of primary care, general psychiatry, and specialist addiction services," Drug and Alcohol Dependence, vol. 134, pp. 92-98, 2014.

[7] A. Bryan, et al., "Drug-related knowledge, attitudes and beliefs in Ireland: report of a nation-wide survey," Dublin, Ireland, The Health Research Board, 2000.

[8] O. A. Ayorinde, et al., "Psychiatric research in Nigeria: Bridging tradition and modernization," The British Journal of Psychiatry, vol/issue: 184(6), pp. 536-538, 2004.

[9] S. Amaele, "Alternative measures for the control of drug abuse in Nigerian school system," International Journal of Academic Research, vol/issue: 4(6), pp. 186-191, 2012.

[10] O. A. Awosusi and J. A. Adegboyega, "Knowledge of health effects and substance use among students of tertiary institutions in Southwestern, Nigeria," Journal of Education and Practice, vol. 4, pp. 23-28, 2013.

[11] A. Abayomi, et al., "Psychosocial correlates of hazardous alcohol use among undergraduates in South Western Nigeria," General Hospital Psychiatry, vol. 35, pp. 320-324, 2013.

[12] C. F. Essien, "Drug use and abuse among students in tertiary institutions- the case of Federal University of Technology, Minna," Journal of Research in National Development, vol/issue: 8(1), 2010.

[13] S. N. Ekpenyon, "Drug abuse in Nigerian schools: A study of selected secondary institutions in Bayelsa state, South-South, Nigeria," International Journal of Scientific Research in Education, vol/issue: 5(3), pp. 260-268, 2012 . 
[14] K. A. Oshikoya and A. Alli, "Perception of drug abuse amongst Nigerian undergraduate," World Journal of Medical Sciences, vol/issue: 1(2), pp. 133-139, 2006.

[15] D. O. Fareo, "Drug abuse among Nigerian adolescent strategies for counseling," The Journal of International Social Research, vol/issue: 5(20), pp. 341- 347, 2012.

[16] A. Adesanya, et al., "Psychoactive substance abuse among inmates of a Nigerian prison population," Drug and Alcohol Dependence, vol/issue: 47(1), pp. 39-44, 1997.

[17] A. O. Pela, "Recent trends in drug use and abuse in Nigeria," Bulletin on Narcotics, vol/issue: 41(1-2), pp. 103-107, 1989.

[18] P. O. Onifade, et al., "A descriptive survey of types, spread, and characteristics of substance abuse treatment centers in Nigeria," Substance Abuse Treatment, Prevention and Policy, vol/issue: 6(25), 2011.

[19] J. Rhodes and L. Jason, "Preventing substance abuse among children and adolescents," New York, NY, Pergamon Press, 1998

[20] B. O. James and J. O. Omoaregba, "Nigerian medical students' opinion about individuals who use and abuse psychoactive substances," Substance Abuse: Research and Treatment, vol. 7, pp. 109-116, 2013.

[21] I. O. Jack-Ide, et al., "Mental healthcare policy environment in Rivers state: Experiences of mental health nurses providing mental health care services in neuropsychiatric hospital, Port Harcourt, Nigeria," International Journal of Mental Health Systems, vol/issue: 7(8), pp. 109-116, 2013.

[22] J. Caplehorn, et al., "Measuring and comparing the attitudes and beliefs of staff working in New York methadone maintenance clinics," Substance Use Misuse, vol. 32, pp. 399-413, 1997.

[23] K. Humphreys, et al., "Recovering substance abuse staff members' beliefs about addiction," Journal of Substance Abuse Treatment, vol/issue: 13(1), pp. 75-78, 1996.

[24] J. N. Chapel, et al., "The substance abuse attitude survey: An instrument for measuring attitudes," Journal of Studies on Alcohol, vol. 46, pp. 48- 52, 1985.

[25] S. Kelleher and P. Cotter, "A descriptive study on emergency department doctors' and nurses' knowledge and attitudes concerning substance use and substance users," International Emergency Nursing, vol/issue: 17(1), pp. 3$14,2009$.

[26] National Institutes of Health \& National Institute on Drug Abuse, "Drug of abuse information," Bethesda, MD, NIDA, 2010.

[27] J. E. B. Harris, et al., "Changing men's male gender-role attitudes by applying the elaboration likelihood model of attitude change," Sex Roles, vol/issue: 35(9), pp. 563-580, 1996.

[28] D. F. McLaughlin, et al., "The perceptions and aspirations illicit drug users hold toward health care staff and the care they receive," Journal of Psychiatric and Mental Health Nursing, vol. 7, pp. 435-441, 2000.

[29] M. K. Hage, et al., "Modifying residents' attitudes about substance abuse treatment and training," American Journal on Addictions, vol. 10, pp. 40-47, 2001.

[30] L. Dixon, et al., "Acute effects of drug abuse in schizophrenic patients: Clinical observations and patients' selfreports," Schizophrenia Bulletin, vol. 16, pp. 69-79, 1990.

[31] W. Hall and L. Degenhardt, "Cannabis use and psychosis: A review of clinical and epidemiological evidence," Australian and New Zealand Journal of Psychiatry, vol/issue: 34(1), pp. 26-34, 2000.

[32] T. H. Moore, et al., "Cannabis use and risk of psychotic or affective mental health outcomes: a systematic review," Lancet, vol. 370, pp. 319-328, 2007.

[33] A. D. Galinsky, et al., "Perspective-taking and self-other overlap: Fostering social bonds and facilitating social coordination," Group Processes and Intergroup Relations, vol. 8, pp. 109-124, 2005.

[34] N. J. Goldstein and R. B. Cialdini, "The spyglass self: A model of vicarious self-perception," Journal of Personality and Social Psychology, vol/issue: 92(3), pp. 402-417, 2007.

[35] W. R. Miller and V. C. Sanchez, "Motivating young adults for treatment and lifestyle change," in G. Howard (Ed.), "Issues in alcohol use and misuse by young adults," Notre Dame, IN, University of Notre Dame Press, 1993.

[36] C. M. Vauclair and R. Fischer, "Do cultural values predict individuals' moral attitudes? A cross-cultural multi-level approach," European Journal of Social Psychology, vol. 41, pp. 645-657, 2011.

[37] F. C. Todd, et al., "Barriers to optimal care for patients with coexisting substance use and mental health disorders," Australian and New Zealand Journal of Psychiatry, vol. 36, pp. 792 - 799, 2002.

[38] C. Chu and A. Galang, "Hospital nurses' attitude toward patients with a history of illicit drug use," The Canadian Nurse, vol/issue: 109(6) pp. 29-33, 2013. 


\section{BIOGRAPHIES OF AUTHORS}

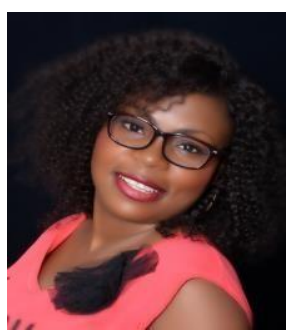

Dr. Olubusayo Akinola is a drug demand reduction expert for the European Union Support Project to the Economic Community of West African States (ECOWAS) "Support to the Regional Action Plan on illicit drug trafficking, related organized crimes and drug abuse in West Africa". Dr. Akinola holds a Ph.D. in Public Health (Epidemiology) from Walden University and a Masters degree in Public Health from the University of East London, United Kingdom. She's currently completing a graduate professional course at Harvard University (HES) in Corporate Sustainability and Innovation. Her level of work-based experience in the region increased her passion for examining harm minimization amongst drug-using populations through effective evidence-based interventions for drug use prevention and treatment. Her research interests include: drug-related epidemiologic methodology, adverse drug reactions, minority health, substance abuse and related disorders.

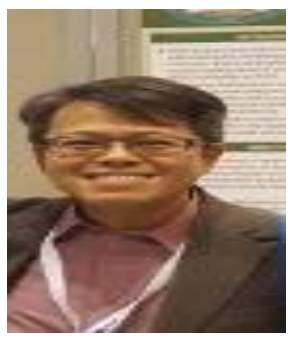

Dr. Wen-Hung Kuo currently works as a contributing faculty at Walden University's College of Health Sciences and a consultant at Medcom Asia. Dr. Kuo received an SM (Master of Science) in Epidemiology from Harvard University's School of Public Health and a Ph.D. from the Department of Mental Health at the Johns Hopkins University Bloomberg School of Public Health. He has published a number of articles and presented in numerous national and international conferences. His research interests include: Epidemiologic methodology, suicidal behavior, depression, drug abuse, HIV/STD, and immigrant and refugee health.

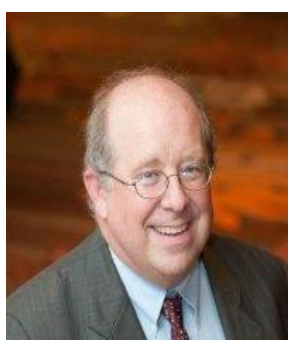

Dr. John Oswald is a senior health care leader with strong interest in global health utilizing extensive abilities in public health leadership, health services research and epidemiology. He has extensive experience in comparative health systems, community health and health statistics. Dr. Oswald received an MPH in Managed Care and Public Health Administration and a Ph.D. in Health Services research and Epidemiology from the University of Minnesota-Twin Cities. After five years (2010-15) working on federal health reform in Washington DC, he returned to Minneapolis- St. Paul, Minnesota to explore global health opportunities working with Minnesota- based and national organizations. In addition to global health development projects, he has extensive responsibilities in public health doctoral programs with teaching and dissertation advising responsibilities.

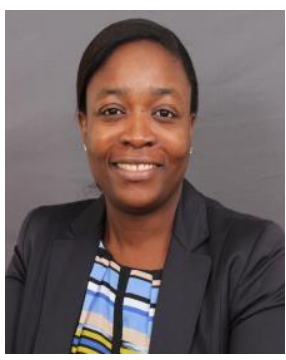

Dr. Olawunmi Obisesan is an adjunct faculty in the Department of Social Work at Southeast Missouri State University, Missouri, USA. Olawunmi holds several degrees including a PhD in Public Health (Epidemiology) from Walden University and a Doctorate in Health Education from

A.T. Still University. Olawunmi has worked with several hospitals, and is currently the Coordinator for the Regional Arthritis Center (RAC) for 18 counties in Southeast Missouri. Under the RAC program, Olawunmi implemented several CDC-funded evidence-based programs for the State of Missouri, including the Stanford University's Chronic Disease Self-Management Program (CDSMP). She has published a number of articles and presented in numerous national and international conferences. Her research interests include issues that affect the health of vulnerable populations, especially immigrants. 